\title{
Produção coletiva em rede: é possível avaliar?
}

\author{
Margarete $\mathrm{Axt}^{1}$, \\ Carime Rossi Elias ${ }^{2}$, \\ Daniela Peño Paiva ${ }^{3}$, \\ Débora F. Martinez ${ }^{4}$, \\ Elisângela C. Lopes ${ }^{5}$, \\ Eunice Polonia ${ }^{6}$, \\ Evandro Alves ${ }^{7}$, \\ Fernando Hartmann ${ }^{8}$, \\ Gislei R. Lazzarotto", \\ Marleni Matte ${ }^{10}$, \\ Sílvia Meirelles \\ Leite $^{11}$
}

\begin{abstract}
Resumo: O presente trabalho tem como objetivo apresentar e refletir sobre uma proposta pedagógica na coexistência com ambientes virtuais interativos para aprendizagem compartilhada de conceitos. O intuito é problematizar a questão da Avaliação no ensino Superior a partir de uma sistematização, por ora ainda parcial, de experiência desenvolvida no decorrer de um semestre letivo, em Curso de Pedagogia, a partir de modalidades avaliativas alternativas que incluem mapeamentos conceituais.

A metodologia se caracterizou pela exploração de possibilidades avaliativas tanto quanto autoavaliativas realizadas ao longo de todo o trabalho, articulando dois níveis distintos de ensino: um grupo da Graduação e um grupo do Pós-Graduação. Os resultados apontam para um uso pedagógico da avaliação em ambientes virtuais de aprendizagem como mais uma possibilidade capaz de potencializar a aprendizagem, levando à construção de conhecimento teórico-conceitual.
\end{abstract}

Palavras- Chave: Avaliação, Pedagogia Universitária, Ensino Superior, Informática na Educação, Educação a Distância, Ambiente Virtual de Aprendizagem.

Collective production: is it possible to evaluate it?

Abstract: The objective of this paper is to present and reflect about a pedagogical proposal in the coexistence of virtual, interactive learning environments for the shared learning of concepts. The aim is to question Evaluation in High Education based on a so far partial systematization of an

${ }^{1}$ Professora do Depto. de Estudos Especializados da Faculdade de Educação/UFRGS. Professora do Programa de PósGraduação em Educação da UFRGS e do Programa de Pós-Graduação em Informática na Educação da UFRGS. Coordenadora do Laboratório de Estudos em Linguagem, Interação e Cognição (LELIC/PPGEdu/UFRGS).

${ }^{2}$ Graduada em Pedagogia. Doutoranda em Educação pelo PPGEdu/UFRGS.

${ }^{3}$ Especialista em Informática na Educação pelo PPGIE/UFRGS. Bolsista AT/CNPq.

${ }_{5}^{4}$ Graduanda em Pedagogia. Bolsista IC/CNPq.

${ }^{5}$ Graduanda em Pedagogia. Bolsista IC/CNPq.

${ }^{6}$ Professora de Inglês no Departamento de Línguas Modernas do Instituto de Letras/UFRGS. Doutoranda do PGIE/UFRGS.

${ }^{7}$ Graduado em Pedagogia. Doutorando em Educação pelo PPGEdu/UFRGS.

${ }^{8}$ Graduado em Psicologia. Formação em Psicanálise. Mestrando em Educação pelo PPGEdu/UFRGS.

${ }^{9}$ Professora do Depto. de Psicologia Social e Institucional do Instituto de Psicologia/UFRGS.

${ }^{10}$ Graduada em Letras. Mestre em Educação e Doutoranda do PPGEdu/UFRGS

${ }^{11}$ Graduada em Jornalismo. Mestranda PPGEdu/UFRGS. 
experience developed during a term in the Pedagogy course using alternative evaluative modalities which include conceptual mappings.

The methodology was characterized by the exploration of evaluative and self-evaluative possibilities accomplished during the whole work, articulating two distinct levels of teaching: an undergraduation group and a post-graduation group.The results point to a pedagogical use of the virtual learning environment evaluation as one more possibility, able to potenciate learning, leading to the construction of conceptual-theoretical knowledge.

Key words: Evaluation, University Pedagogy, High Education, Computing in Education, Distance Education, Virtual Learning Environment.

\section{Apresentação}

Ao atravessarem o funcionamento escolar, as tecnologias digitais da comunicação e da informação produzem sentidos, potencializam e atualizam transformações, constituindo uma verdadeira ecologia ${ }^{12}$ que, em gerando efeitos inesperados no campo educativo, gera também novas questões a serem pensadas pelos educadores. Mas, se por um lado, elas trazem novos desafios para a área educacional, não dispensam outras problemáticas mais antigas e específicas deste campo de conhecimento.

Nesta perspectiva, apresentam-se, mais uma vez, alguns dos mesmos interrogantes que têm perpassado a Educação, porém, agora, referindo-se mais especificamente a ambientes virtuais de aprendizagem, sobretudo os que se pretendem interativos:

- será possível que alunos de ensino superior possam construir conhecimento conceitual, num ambiente virtual interativo pautado privilegiadamente em trocas dialógicas?

- como avaliar objetivamente a construção conceitual, tanto coletiva, quanto de cada aluno em particular, sem desrespeitar esta recente direção que temos tomado como abordagem metodológica em ambientes virtuais, calcada nos pressupostos da cooperação e do pensamento autoral, a partir da interação entre uma multiplicidade heterogênea de pontos de vista?

- seguindo a perspectiva colocada, quais processos avaliativos podem ser aí convocados de tal modo que contribuam, à sua maneira, não apenas para classificar desempenhos numa escala de valores, mas para potencializar as próprias aprendizagens dos conteúdos previstos pela disciplina?

O presente trabalho tem como objetivo apresentar e pensar uma proposta pedagógica, em ambientes virtuais interativos para aprendizagem compartilhada de conceitos, que problematize a questão da Avaliação no Ensino Superior.

$\mathrm{O}$ argumento central será que a partir da articulação entre uma concepção interativa de ambiente virtual e uma proposta pedagógica, apoiada na cooperação dialógica e na multiplicidade heterogênea de pontos de vista, cria-se uma ecologia propícia ao desencadeamento de processos avaliativos. Tal ecologia teria força para interferir, enquanto função, na própria processualidade do movimento de aprender, ajudando-o a se constituir.

Esse estudo versa sobre de uma sistematização, por ora ainda parcial, de uma experiência pedagógica desenvolvida no decorrer de um semestre, com 25

\footnotetext{
${ }^{12}$ Uma abordagem ecológica da cognição preconiza relevar, quando das análises sobre a produção do conhecimento, as mútuas inter-relações entre múltiplos sujeitos e objetos/tecnologias disponibilizados em um determinado contexto espaço-temporal, institucional-cultural e cognitivo-social (Maraschin; Axt, 1998). 
alunas, em disciplina obrigatória do curso de Pedagogia. Essa experiência contou com o aporte de um grupo de interlocução, de 9 alunos, instituído no nível da pós-graduação a partir de proposta de seminário de pesquisa. Além dos alunos de Pós-Graduação, participaram do grupo de intrelocução dois bolsistas de nível de graduação ${ }^{13}$. A responsabilidade desse grupo era, junto à disciplina da graduação, trabalhar, concreta e ativamente, na criação das condições de possibilidade para a emergência da função de autoria, no âmbito do espaço virtual de aprendizagem, bem como buscar, pela avaliação, os resultados obtidos em termos de conhecimento construído.

Desse modo, o lugar de escrita dos autores desse artigo, tanto do grupo de interlocução, quanto da docente responsável pelas ofertas curriculares nos dois níveis, é de implicação na experiência em questão, desde antes mesmo do início da mesma. Cabe mencionar que o referido grupo, além de ter vivenciado esta experiência juntamente com as alunas da graduação, foi também interlocutor da própria docente, tendo participado das reuniões de planejamento e de todas as discussões teórico-metodológicas que deram sustentação à continuidade desse trabalho.

\section{Delineando a ecologia}

A par das reuniões de estudo e planejamento com os estudantes da pósgraduação com vistas à sustentação da experiência, a proposta pedagógica contava com momentos de encontro presencial, em que se reuniam, em um mesmo horário, os dois grupos de alunos - graduação e pós-graduação. Esses encontros tinham por objetivo desenvolver os conteúdos da disciplina em nível de graduação através de discussões de cunho teórico-metodológico, em especial pela via do envio de mensagens escritas para ambiente virtual.

Embora o envio de mensagens fosse a via preferencial tomada para o desenvolvimento das reflexões propostas (tanto na modalidade síncrona, às segundasfeiras pela manhã, quanto na assíncrona durante a semana), não era a única. Realizavam-se também: reuniões presenciais em grande grupo, sem as tecnologias digitais para tratar, por via da oralidade, questões teóricas, tópicos relativos à avaliação dos processos emergentes em razão das articulações em curso e propostas de novas atividades; reuniões presenciais em pequenos grupos, em que se discutiam e se elaboravam os trabalhos específicos a esses pequenos grupos, inclusive a confecção de homepages.

Contudo, privilegiaremos, no presente trabalho, a interação no ambiente virtual e dentre os espaços do ambiente virtual, privilegiaremos o espaço de interação denominado de "Compartilhando Interrogantes", resultado de uma composição híbrida a meio caminho entre um fórum, um chat e um mural eletrônico (um for-chat) ${ }^{14}$, permitindo o registro das contribuições, tanto síncronas, quanto assíncronas.

\footnotetext{
${ }^{13}$ Além desses bolsistas, na construção do ambiente, esteve envolvida uma equipe de bolsistas-colaboradores, vinculados ao LELIC/PPGEdu/UFRGS.

${ }^{14}$ Software de comunicação interativa e dialógica à distância e on-line, capaz de suportar a entrada simultânea de muitos participantes e de ser rapidamente atualizada em terminais por linha discada. Maiores informações sobre o for-chat em STUERMER-DAITX (2002). Cabe ressaltar que em dois outros momentos do presente Ciclo de Palestras sobre Novas Tecnologias na Educação do UFRGS/CINTED, o for-chat será mencionado: na palestra "For-chat: uma comunidade virtual construindo sentido, autoria e conceitos através do discurso em um ambiente cooperativamente interativo", tendo como autoras Querte Mehlecke, Liane Tarouco e Margarete Axt (25/02/2003, das 10:40 às 11:20) e 
Nesse for-chat, as mensagens ficam exibidas assim que são enviadas e todas podem ser lidas independentemente do momento em que são acessadas. Elas ficam distribuídas no formato de um grande texto, com a possibilidade de se contribuir nos intervalos entre cada uma das contribuições. Os registros são armazenados por semana, as mensagens sendo postadas sempre na semana em curso. Para facilitar o acesso às contribuições publicadas, o próprio sistema atualiza a página a cada envio, disponibilizando as mensagens mais recentes ${ }^{15}$.

É importante salientar o caráter de processualidade das configurações, tanto do ambiente virtual, quanto das práticas pedagógicas que aí se instalaram, que foram sofrendo ajustes durante todo o semestre, em decorrência das contínuas avaliações, por parte das alunas da graduação, do grupo de interlocução e da equipe de apoio técnico.

\section{Da problematização dos processos avaliativos}

Em um modelo de trabalho pedagógico mais tradicional, fundamentado em uma concepção de conhecimento como transmissão de conteúdos, a avaliação costuma ser operacionalizada a partir da "observação do comportamento esperado do aprendiz". Deste modo, os dispositivos avaliativos utilizados terão como objetivo mensurar o apreendido, espelhando a ótica única do docente sobre o conteúdo explorado, baseada em suas certezas prévias de condução do ensino, na qual só há um caminho possível a ser trilhado pelos aprendizes.

Nesse tipo de avaliação, os alunos diferenciam-se pelo lugar que ocupam na classificação, cujo critério é a proximidade ou não para com o "certo", o "verdadeiro", estes valores sendo, via de regra, definidos pelo professor e consignados em aula. Esteban (2001, 15-16) aponta que:

A avaliação escolar, nesta perspectiva excludente, silencia as pessoas, suas culturas $e$ seus processos de construção de conhecimentos; desvalorizando saberes, fortalece a hierarquia que está posta, contribuindo para que diversos saberes sejam apagados, percam sua existência e se confirmem como a ausência de conhecimento.

Já numa avaliação de caráter mais ecológico, ou sistêmico, afinada com os pressupostos das teorias da complexidade ${ }^{16}$, deixa-se de lado a ênfase no desempenho individual do aluno e na quantidade de acertos/erros que apresentará em razão de um comportamento já de antemão definido: desloca-se o foco de observação para aqueles elementos - indivíduos, objetos e relações - que aí se estabelecem e se articulam, configurando uma determinada situação de aprendizagem, da qual deriva/emerge um certo modo de aprender, de conhecer. Tem-se, em outras palavras, um conjunto de elementos, caracterizando um contexto sistêmico-ecológico complexo, atravessado por

\footnotetext{
"Software de Comunicação For-Chat", tendo como autores Daniela Peño Paiva, Fábio Medeiros, Margarete Axt e Tiago Stürmer Daitx (26/02/2003, das 11:20 às 12:00).

${ }^{15}$ Foram disponibilizados outros espaços de contribuição, não apenas nesta modalidade, mas na forma de interface para envio de arquivos HTM para confecção de homepages, ou como estrutura de banco de dados tendo em vista a criação de uma biblioteca virtual de resenhas, sinopses e fichamentos dos textos lidos e discutidos pelos dois grupos (graduação e pós-graduação). Estes não estão no escopo de análise do presente artigo.

${ }^{16}$ Uma abordagem complexa se fundamenta sobre as relações entre as partes e a totalidade, e versa que o todo é qualitativamente diferente que a soma das partes, de forma que essa totalidade se apresenta, ao mesmo tempo, maior ou menor do que a soma das partes. Por outro lado, cada uma dessas partes, ao mesmo tempo, conserva a sua singularidade e a sua individualidade e, de algum modo, contém o todo. Uma relação complexa surge, "onde quer que se produza um emaranhamento de ações, de interações e de retroações". (Morin; 1996; p.274).
} 
um modo de funcionamento específico. Desenha-se, então, como pressuposto, para cada sujeito aprendiz particular, embora no interior de uma coletividade, um contexto de aprendizagem, único e singular, na medida em que cada um deverá ocupar, na configuração momentânea criada em tal contexto, uma certa posição de onde pode e se autoriza/é-autorizado a falar.

No conjunto dessas reformulações, a avaliação poderá, então, ser concebida como um processo que emerge dos, e retorna sobre os, próprios processos de funcionamento cognitivo voltados à construção do conhecimento ${ }^{17}$, no interior de uma dada ecologia. Pode, assim, tornar-se um mecanismo, não somente de apreciação, pelo observador externo, dos processos construtivos passíveis de se manifestarem na configuração momentânea do contexto sistêmico; mas, muito mais, um mecanismo que integra a própria construtividade, potencializando-a, na medida em que implica, no processo, o aprendiz, desvelando/revelando-lhe percursos trilhados, estes constituindo marcas que historicizam movimentos da aprendizagem que levam à construção conceitual.

Em nossa experimentação, o for-chat possibilitou a elaboração de dispositivos avaliativos, em consonância com a última perspectiva, na qual a avaliação reverte em aprendizagem, não sendo apenas mecanismo de mensuração. Em outras palavras, foi possível, no espaço pedagógico interativo do for-chat, privilegiar a ação, a construção de um saber crítico, entendendo o aprendizado calcado na própria avaliação, aqui, como efeito, e ao mesmo tempo como processo de subjetivação que determina modos de funcionamento no interior do dispositivo ecológico-sistêmico, e não apenas como preservação da memória.

\section{Avaliação: possíveis percursos}

Uma das peculiaridades que caracterizou o uso do ambiente virtual articulado com a proposta pedagógica em discussão foi a possibilidade de ressignificação das ferramentas disponíveis, no que tange aos processos avaliativos.

Por exemplo, o registro escrito das contribuições dos participantes desta ecologia permitiu acompanhar como estavam sendo argumentados e construídos os conceitos, na medida em que estes se constituíram como fruto de elaboração de cada um dos envolvidos e do grupo como um todo. Como uma das alunas da graduação coloca no decorrer do debate:

"A avaliação deve ser encarada como um processo de repensar, de rever a prática (no caso do professor) e não avaliação no sentido de notas, conceitos (no caso do aluno) mesmo porque o processo de "avaliação" do desenvolvimento do aluno é muito amplo e varia de acordo com cada sujeito.(... $)^{\prime \prime 18}$

A permanência dos registros no ambiente possibilitou, além do acompanhamento pelo outro, também um repensar o próprio processo pelo participante no seu envolvimento com processos auto-avaliativos, uma vez que era possível voltar ao que havia sido escrito e rever ou acrescentar às colocações.

Com as contribuições separadas por semana, e não por temáticas, o debate não ficou segmentado por assuntos específicos, pré-determinados, ainda que alguns pontos

\footnotetext{
${ }^{17}$ Ver Axt and Maraschin (1997).

${ }^{18} \mathrm{~A}$ escrita dos participantes não foi alterada.

V. 1 № 1 , Fevereiro, 2003
} 
temáticos tivessem adquirido maior intensidade nas discussões. Esta característica, que reputamos à especificidade do for-chat, parece ter interferido de modo particular nas possibilidades avaliativas e auto-avaliativas do grupo: mas como a ferramenta for-chat estava também no formato de um fórum, era possível escolher em que local do texto a mensagem seria inserida, dispersando as contribuições nos diferentes espaços e rompendo com uma certa linearidade do debate.

Ao mesmo tempo, a construção, sendo coletiva/polifônica, privilegiou o diálogo entre os múltiplos e heterogêneos pontos de vista dos participantes, construídos nos entrecruzamentos da sua experiência no cotidiano escolar com as leituras dos diferentes autores (indicados nesta, ou até em outras disciplinas) e as trocas na rede pela via escrita.

A ruptura da linearidade, a dispersão, a multiplicidade e a heterogeneidade podem levar à contradição ou aos paradoxos. Em decorrência, produzem desequilíbrios $\operatorname{cognitivos}^{19}$ de maior ou menor intensidade, podendo afetar o campo contextualizado das aprendizagens de cada participante: é nesse sentido, então que o captura em processos de construção e de retorno sobre o construído, na tentativa (vã!) de estabelecer coerências, consistências e completudes ${ }^{20}$. Todavia, considera-se que tenha sido justamente este esforço que possibilitou a ampliação conceitual das discussões teóricas realizadas, contribuindo para o processo de construção individual/coletiva de conhecimento dos participantes. Neste sentido, a ruptura com uma pretensa unidade do saber interferiu no processo avaliativo, potencializando a construtividade/criatividade.

Em conseqüência da atenção dispensada à proposição de percursos reflexivos afinados à específica situação de aprendizagem, acabaram por serem propostos, na processualidade da experiência pedagógica, quatro modalidades avaliativas e/ou autoavaliativas $^{21}$ :

- $\quad$ Os percursos conceituais individuais emergiram como modalidade avaliativa desenvolvida pelo grupo de interlocução com base na avaliação de contexto das falas individuais de cada participante no for-chat após as primeiras seis semanas de aula. $\mathrm{O}$ intuito foi o de resgate dos conceitos discutidos, por participante, procurando captar uma certa unidade nos aspectos teóricos individuais, e deste modo emprestar uma certa visibilidade aos caminhos até então produzidos. Surgiu de dentro do funcionamento sistêmico-ecológico, como primeiro processo avaliativo, em consideração às colocações de algumas alunas que se diziam "perdidas" em re lação à quantidade e à complexidade dos assuntos abordados.

- Os memoriais individuais de conceitos emergiram na continuidade, como processo auto-avaliativo, em resposta a uma necessidade de conhecer o ponto de vista das próprias alunas sobre a experiência vivenciada e a construção de seu próprio micro-

\footnotetext{
19 Muitos trabalhos de concepção construtivista, envolvendo aprendizagens e construção de conhecimento em ambientes virtuais (mas também convencionais) apostam na tese piagetiana de condições de perturbação e conflitos cognitivos como ponto de partida para promoção do processo construtivo. Entre estes trabalhos, ver a produção significativa do LEC/UFRGS (Laboratório de Estudos Cognitivos), além da apresentada por outros grupos de pesquisa nesta linha construtivista (ver anais SBIE 2001); também a produção do LELIC/UFRGS (Laboratório de Estudos em Linguagem Interação e Cognição) vem trazendo evidências em favor desta tese, enquanto aliada a outros pressupostos buscados em diálogos com autores contemporâneos, tais como Deleuze, Bakhtin, Pêcheux...

${ }^{20}$ Para desenvolvimento deste argumento, entre outros, Axt and Maraschin (1999), Axt and alii (2001).

${ }^{21}$ Além dessas modalidades havia a proposição de um trabalho final que consistia na construção e publicação de páginas na Internet contendo as pesquisas realizadas pelos pequenos grupos e que já estava prevista no plano da disciplina. 
sistema conceitual. Consistiu na elaboração e publicação de textos que, ao mesmo tempo:

(a) resgatassem, através de falas registradas, suas próprias trajetórias nas discussões conceituais, conforme o depoimento de uma das alunas:

(...) Através da leituras [sic] dos textos sobre psicopedagogia mudei um conceito que tinha de que somente a escola (o sistema) era o responsável pelo fracasso do aluno. Pude notar que existem inúmeros fatores que influenciam isto. Tem a relação do professor com o aluno, a relação da família, a relação do aluno com a aprendizagem. Enfim é toda uma rede interligada e uma influencia as outras. (...)

(b) construíssem considerações a respeito da proposta da disciplina a partir dos modos como cada uma havia sido afetada, através de questionamentos, críticas ou outras formas de manifestação.

(...) Durante as primeiras aulas estive insegura sobre como seria meu desempenho durante este semestre, afinal teria que expor minhas dúvidas, certezas $e$ questionamentos para uma "máquina". Mesmo sabendo que "por trás" dela haveriam [sic] pessoas, uma máquina jamais seria capaz de retribuir, mesmo que com uma cara feia, as minhas colocações. (...)

- Os mapeamentos conceituais-coletivos emergiram como processo avaliativo novamente sob a responsabilidade do grupo de interlocução, já ao final do semestre. Pelo resgate dos conceitos que foram articulados nos for-chats, em especial no espaço "Compartilhando Interrogantes", construíram-se mapas conceituais ${ }^{22}$, cujo objetivo foi reconstituir o conjunto da produção conceitual na disciplina (não mais de cada participante), bem como a forma como estes conceitos se relacionavam entre si também no seu conjunto. Esta modalidade, que se insere no espírito de funcionamento das redes virtuais, mostrou-se extremamente fecunda na identificação dos percursos conceituais produzidos na disciplina e será melhor desenvolvida na próxima secção deste artigo.

- $\quad \mathrm{O}$ memorial avaliativo individual final emergiu, por um lado, em continuidade ao memorial individual de conceitos, segunda modalidade acima relatada; diferenciou-se desta pela maior completude do trabalho, na medida em que deveria referir-se à experiência de cada um no seu todo. Por outro lado, contribuiu ao enriquecimento da avaliação do próprio sistema de conceitos, pela possibilidade de colocação dos mesmos em forma de um mapeamento conceitual, semelhante, ou não, ao realizado pelo grupo de interlocução. Em um destes textos, uma aluna escreve sobre a vivência:

Repensando sobre a nossa caminhada durante este semestre, nesta disciplina, e especificamente ao realizar este memorial de fechamento de nossas aulas, estou ciente de que vivenciamos algo diferente em nossas carreiras acadêmicas: diferente, difícil, impulsionador e até mesmo, desafiador...(...)

\footnotetext{
${ }^{22}$ Mapa conceitual é como se tem denominado a organização dos conceitos numa forma relacional e modular, em classes e subclasses (Amoretti; Tarouco 2000: 67). Além dessa conceituação, recorremos, a partir de Barnes (1986) e suas apreciações sobre a teoria das revoluções científicas de Kuhn, a uma consideração de tais mapas enquanto tramas conceituais. Essas tramas se cambiariam e se reconfigurariam a cada novo elemento posto em relação, ou ainda do deslocamento dos elementos já existentes, no interior de uma determinada comunidade e seu contexto. Cabe mencionar que, neste trabalho, entendemos mapas conceituais-coletivos como sendo aqueles construídos com base nos conceitos discutidos por todos os participantes no ambiente virtual.
} 
Cabe destacar que os deslocamentos propostos por este trabalho avaliativo não afetaram da mesma maneira todos os participantes. Fragmentos de depoimentos de alunas ajudam a ilustrar algumas das dificuldades encontradas. Em relação ao modo de formalização da disciplina ainda no momento da matrícula, declara uma aluna:

(...) Apesar das dificuldades que tenho em operar o computador, acredito que a experiência foi válida e importante para a nossa formação profissional. Entretanto acredito que a informação sobre esta nova, ou inovadora, maneira de ensinar $e$ aprender deva ser informada no momento da matrícula. Digo isso, porque o contato com essa nova metodologia deve ser espontâneo para que a produção e o desenvolver da disciplina seja prazeroso. (...)

Outra aluna, discutindo sobre a questão da autoria e referindo-se à forma de exposição "pública" exigida pela participação nos for-chats, escreve:

(...) Outro ponto é a dificuldade que temos em nos assumirmos autores. Acho que essa dificuldade vem do medo que temos do que pode vir após assumirmos a autoria de algo. (...)

Outra ainda, revendo o seu processo no decorrer da disciplina, percebe um deslocamento operado em seu próprio modo de funcionamento:

(...) Após o primeiro memorial e de uma reflexão sobre os ditos a respeito das dificuldades de todos, busquei tentar mudar e passar a ser mais um desses inibidos que resolveram buscar a construção desse conhecimento, através dessa rede tecida por nós; dialogando com os autores e nas trocas com os grupos. (...)

Em relação ao mapeamento de percursos conceituais individuais produzidos no decorrer da disciplina, uma das alunas, ao rever seus próprios registros, construiu um mapa onde diferentes conceitos como, por exemplo, afetividade, aprendizagem, psicopedagogia, intervenção, avaliação, colocam-se em relação - conforme é possível observar na figura a seguir (Figura 1).

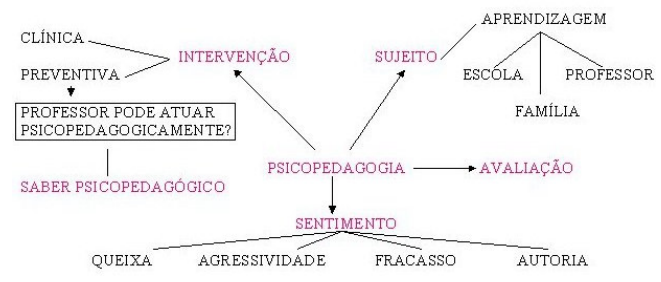

Figura 1: Exemplo de mapeamento conceitual, constante no memorial avaliativo individual final.

Referindo-se a esta meta-reflexão e considerando o conceito de autoria, a aluna escreve: (...) A AUTORIA é um assunto que considero super importante e me marcou muito também pela falta que sinto de não ter sido trabalhado no meu primeiro e segundo grau. Acredito que é por causa disto que sinto uma enorme dificuldade de produzir algo totalmente meu, também pela insegurança de não me sentir capaz. A escola deve dar um sentido para o aprendizado da leitura e da escrita (...)

Por fim, a única modalidade avaliativa proposta explicitamente ao grupo da graduação desde o início da disciplina. As alunas dividiram-se em pequenos grupos e pesquisaram diferentes temas, dentro do programa da disciplina, construíram páginas na Internet de cada grupo e socializaram os resultados dos trabalhos. Nestes trabalhos, algumas delas conseguiram articular os conceitos elaborados nas discussões nos for- 
chats com a sua prática docente, numa ação ressignificada pelos deslocamentos que a vivência na disciplina, de algum modo, ajudou a construir.

\section{Da construção dos mapeamentos conceituais-coletivos}

Como estratégia de construção dos mapeamentos conceituais-coletivos, o grupo de interlocução chegou à definição inicial de um conjunto de conceitos-chave, extraídos a partir de "varreduras" efetivadas nos for-chats com o objetivo de levantar os conceitos mais visíveis.

Sublinha-se este como primeiro ponto, inquietante, da tarefa, que foi: como escolher ou identificar quais eram estes conceitos-chave das discussões. Ao mesmo tempo, esta fase de construção dos mapeamentos conceituais permitiu que "brincássemos" com o que chamamos posteriormente de Caça-Palavras, em busca dos conceitos mais relevantes nos registros das contribuições do grupo. Mediante muitas leituras e releituras dos textos nos for-chats foi finalmente possível determinar conceitos que se destacaram nas discussões e distribuí-los entre os participantes do grupo de interlocução pelo critério de interesse pessoal.

Cresceram e agigantaram-se conceitos como Aprendizagem, Avaliação, Autoria, Escuta, Intervenção, Processo, Fracasso, Autonomia, Interação, Psicopedagogia. Cada integrante do grupo de interlocução responsabilizou-se pelo mapeamento de um conceito-chave, caçado, buscando capturar, não só os inter-relacionamentos com outros tantos conceitos, mas ainda o modo como se conectavam aos conceitos-chave.

Deste momento em diante, cada um fez uso de estratégias próprias para dar conta dessa segunda tarefa que era a construção do mapeamento propriamente dito. O objetivo comum era que se pudesse dar visibilidade a percursos conceituais e a construções de saberes sobre determinado ponto dentro dos for-chats, através da diversidade de perspectivas. Decidiu-se que uma forma gráfica poderia tornar mais clara a exposição ao grande grupo e proporcionar uma melhor visualização das discussões conceituais produzidas nos for-chats. Optou-se então, pela forma de mapeamentos conceituais gráficos para apresentar os percursos de cada conceito e seus inter-relacionamentos.

Observa-se que, entre outras coisas, esses mapeamentos mostraram, de maneira acentuada, o caráter polifônico da construção conceitual, em que as expressões pesquisadas eram apresentadas dentro de diferentes enfoques ${ }^{23}$. A construção destes mapeamentos conceituais gráficos não ficou restrita a um software, o que possibilitou diferentes formas de estruturar os percursos: foi usado, tanto o Cmap Tools ${ }^{24}$, quanto editores gráficos e softwares destinados à construção de apresentações, como o PowerPoint. Esta pluralidade de ferramentas pode ser observada nos diferentes formatos dos mapas apresentados.

A seguir apresentamos um exemplo de mapeamento conceitual-coletivo referente ao conceito de fracasso e produzido por uma das integrantes do grupo de interlocação. As dez primeiras semanas de debates nos for-chats foram o objeto de estudo deste conceito. Após a localização e seleção do conceito, acompanhado do seu

\footnotetext{
${ }^{23}$ Ressaltamos que tais enfoques são uma interpretação dos registros e que poderiam ser feitas diferentes leituras das contribuições nos for-chats.

${ }^{24}$ Cmap Tools é o software desenvolvido pela Universidade de West Florida para a construção de mapas conceituais (Amoretti; Tarouco 2000). De acordo com um dos responsáveis por seus desenvolvimentos e aplicações, Alberto J. Cañas (palestra e minicurso no [SBIE-2001], Vitória-ES), o Cmap Tools, disponível no endereço http://cmap.coginst.uwf.edu, vem sendo desenvolvido e usado para representar e compartilhar modelos de conhecimento em diferentes campos da Ciência e da Educação. 
contexto de "falas", proc edeu-se a uma análise de seus possíveis sentidos, os quais apontaram para a existência de referências a diversos tipos de fracasso: escolar, profissional, das avaliações, entre outras categorias. Estas categorias deram origem a um pequeno texto que serviu de guia para a construção do mapa, no programa CMap Tools, que deu a forma cartográfica (Figura 2) que a autora do percurso pensou ser adequada para as discussões trazidas pelos for-chats.

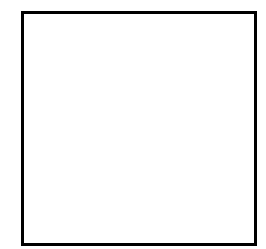

Figura 2: Mapeamento Conceitual relativo ao conceito de Fracasso

Todos os mapeamentos realizados foram disponibilizados na rede, no endereço www.lelic.ufrgs.br/grupo0 , cuja página inicial teve o formato de um Caça-Palavras, numa analogia ao processo vivenciado pelos autores dos mesmos, na primeira fase desta tarefa, e, ao mesmo tempo, retomando a idéia inicial de buscar, dentro das contribuições feitas, os conceitos que se destacaram, sem fechar a possibilidade de outras palavras serem 'caçadas'. Este formato também possibilitou exprimir as idéias do grupo em relação aos (entre)cruzamentos dos percursos conceituais entre si. Nos for-chats nenhum dos conceitos circulou sozinho. Estiveram sempre imbricados a outros conceitos.

Deste modo, os mapeamentos conceituais gráficos construídos foram resultado de várias fases interpretativas, complexificando em muito a tarefa dos autores, pois as configurações daqueles se modificavam a cada nova leitura e a cada discussão feita com os colegas: tivemos que transformar idéias, geralmente amplas, em mapas muito mais resumidos do que gostaríamos que fossem. A modelagem final, como pode ser vista no site, mostrou a diversidade dos olhares e perspectivas que deram a esta última versão da página um caráter inacabado onde há complementos, links, linhas e palavras ainda por serem 'caçados'.

\section{Considerações finais}

Conceber a avaliação, não como a análise de resultados de desempenho, mas como uma parte integrada ao próprio processo de construção de conhecimento no contexto da aprendizagem, mudou a abordagem e a utilização deste conceito. Ou seja, foram as diferentes perspectivas e constantes reflexões - das alunas da graduação, do grupo de interlocução e da professora coordenadora - em relação aos movimentos produzidos pelo grande grupo no decorrer da experiência que, articuladas à fundamentação teórico-metodológica, direcionaram as atividades propostas.

Um dos aspectos que oportunizou olhar a avaliação de um outro lugar, com outro objetivo, e construir uma instrumentalização através caminhos alternativos, foi poder retornar aos registros das discussões. Nisso sobressai-se a concepção de for-chat utilizada, essencial nesta experiência.

A experiência também foi favorecida pela multiplicidade de perspectivas concretas assumidas nas interações, resultado obtido na articulação entre a PósGraduação e a Graduação. A participação do grupo de pós-graduandos e de bolsistas 
permitiu que a avaliação não se restringisse a uma única pessoa, e, deste modo, multiplicaram-se exponencialmente os pontos de vista e as posições de onde se-fala/sepode-falar, bem como se ampliaram as possibilidades virtuais interpretativas do que estava sendo colocado. Como evidência, destaca-se a quantidade de conceitos, bem como a diversidade de percursos conceituais trilhados pelas alunas do curso de Graduação, capturados nos diferentes processos avaliativos propostos e aqui rapidamente expostos.

A perspectiva de uma concepção de aprendizagem como construção individual/coletiva (e não como recepção) conduziu, nesta proposta, a uma experimentação que buscou um certo deslocamento no papel do professor. Ao invés de centralizarem as decisões e se responsabilizarem pela suposta transmissão do conhecimento, a professora-coordenadora, bem como o grupo de interlocução, procuraram contribuir teoricamente nos for-chats a partir de seus lugares concretos, como sujeitos em função-autor-leitor, numa relação que buscava pautar-se pela reciprocidade e pelo respeito às "falas" registradas das alunas da graduação, procurando, não impor uma interpretação, mas compor pela interpretação e produção, o grande texto de discussões conceituais.

Diante da proposta pedagógica vivenciada, mediada pelo for-chat, talvez seja possível ressaltar as formas de avaliação que foram viabilizadas a partir deste sistema de comunicação. Ou seja, a partir da pergunta, sempre recolocada, sobre como avaliar, experimentamos uma avaliação que não se pretende unívoca, que se abre também à intervenção, contribuindo para o processo de aprendizagem não somente no final de uma etapa, mas durante o desenvolvimento da construção do conhecimento. Neste sentido, tanto avaliação, quanto auto-avaliação, reverteram reflexivamente, dobraramse, sobre os processos de construção conceitual, potencializando-os: na medida em que favoreceram o entendimento de quais conceitos estavam se formando, e de como se estavam estabelecendo relações entre conceitos, contribuíram para novas produções e processos avaliativos.

\section{Referências Bibliográficas}

AMORETTI, Maria Suzana Marc; TAROUCO, Liane. Mapas conceituais: modelagem colaborativa do conhecimento. IN: Informática na Educação: teoria e prática. Porto Alegre, vol. 3, nº 1, 2000.

AXT, Margarete ; MARASCHIN, Cleci. Prática pedagógica pensada na indissociabilidade conhecimento-subjetividade. In: Educação e Realidade. Porto Alegre, v. 22(1):57-80. jan/jun. 1997.

AXT, Margarete; MARASCHIN, Cleci. Narrativas Auto-Avaliativas: categorias operativas auto-poiéticas de conhecimento. In: Revista das Ciências Humanas. Florianópolis: UFSC. 1999. Número especial Informática na Educação.

AXT, Margarete and alii. Era uma vez... Uma narrativa em co-autoria no espaço virtual In: SIMPÓSIO DE INFORMÁTICA EM EDUCAÇÃO, 13. 2001. Vitória. Anais. Vitória: Simpósio De Informática Em Educação, 2001, p.136-144.

BARNES, Barry. T. S. Kuhn y las Ciencias Sociales. Mexico: Consejo Nacional de Ciencia e Tecnologia/Fondo Nacional de Cultura. 1986. 
ESTEBAN, Maria Teresa. A avaliação no cotidiano escolar. In: Esteban, Maria Teresa (org). Avaliação: uma prática em busca de novos sentidos. pp. 7-28. Rio de Janeiro: DP\&A. 2001.

MARASCHIN, Cleci ; AXT, Margarete. Conhecimento. In : JACQUES, Maria da Graça Corrêa et alli (orgs). Psicologia Social Contemporânea, livro-texto. Petrópolis : Ed. Vozes. 1998.

MORIN, Edgar. Introdução ao Pensamento Complexo. Lisboa : Ed. Instituto Piaget. 1991.

SIMPÓSIO BRASILEIRO DE INFORMÁTICA NA EDUCAÇÃO. ANAIS

SIMPÓSIO BRASILEIRO DE INFORMÁTICA NA EDUCAÇÃO, 13, Vitória: UFES. nov. 2001.

STUERMER-DAITX, Tiago. Desenvolvimento do software de comunicação "Forchat" [resumo]. In: Salão de Iniciação Científica (14. : 2002 : Porto Alegre) Livro de resumos. Porto Alegre : UFRGS/PROPESQ, 2002. p. 772 